\title{
HAND, FOOT AND MOUTH DISEASE
}

\section{WHAT IS HAND, FOOT AND MOUTH DISEASE?}

Hand, foot and mouth disease is generally a mild illness caused by viruses called coxsackievirus or enterovirus. It is not a serious illness and has nothing to do with the animal disease called foot and mouth disease. It mainly occurs in children under 10 years of age but can also occur in older children and adults.

\section{HOW CAN IT AFFECTYOU?}

Coxsackievirus or enterovirus infection may cause no symptoms at all or only very mild symptoms. When symptoms do occur, they include blisters that start as small red dots which later become ulcers. Blisters appear inside the cheeks, gums, and on the sides of the tongue, as well as on the hands and feet. In infants, sometimes blisters can be seen in the nappy area. Blisters usually last for seven to 10 days. Children can sometimes have a low fever, sore throat, tiredness, feel off colour and may not eat for a day or two. Very rarely, the coxsackieviruses can cause other illnesses that affect the heart, brain, or lining of the brain (meningitis), lungs, or eyes.

\section{HOW COMMON IS IT?}

Hand, foot and mouth disease is a common disease and outbreaks may occur among groups of children; for example, in child care centres.

\section{HOW IS THE INFECTION SPREAD?}

Hand, foot and mouth disease is usually spread by personto-person contact. The virus is spread from the faeces of an infected person to the mouth of the next person by contaminated hands. It is also spread by secretions from the mouth or respiratory system, and by direct contact with the fluid in blisters.

It usually takes between three and five days after contact with an infected person before blisters appear. As long as there is fluid in the blisters, they remain infectious. The virus can remain in faeces for several weeks.

\section{HOW IS ITTREATED?}

Usually no treatment is needed. Paracetamol will relieve fever and discomfort. Do not give children aspirin. If the headache is severe, or if fever persists, consult a doctor.

\section{HOW CAN IT BE PREVENTED?}

- Good hygiene is the best protection: wash hands with soap and water after going to the toilet, before eating, after wiping noses, and after changing nappies or soiled clothing.

- Avoid sharing cups, eating utensils, items of personal hygiene (for example: towels, washers and toothbrushes), and clothing (especially shoes and socks).

- Thoroughly wash any soiled clothing.

- Ensure the mouth and nose are covered when coughing and sneezing. Wipe the nose and mouth with tissues, dispose of used tissues and then wash your hands.

\section{HOW CAN SPREAD OFTHE DISEASE BE CONTROLLED?}

Children with hand, foot and mouth disease should be excluded from school or childcare facilities until their blisters have dried.

The illness should be reported to the director of the childcare centre or school principal.

For more information contact your local public health unit, community health centre, or doctor.

April-May 2003 \& 